\title{
Impairment, disability, and handicap associated with hearing problems and voice disorders among Colombian teachers
}

\section{Deficiencia, discapacidad y minusvalía asociadas a los problemas de voz y audición en profesores colombianos}

\section{Lady Catherine Cantor-Cutiva ${ }^{1,2}$ iD $\otimes$, Diana Elizabeth Guervo-Diaz ${ }^{3}$ iD $\otimes$, Eric J. Hunter $^{4}$ (D) H, $^{\circ}$ Marisol Moreno-Angarita ${ }^{5}$ (D) $(0)$}

${ }^{1}$ Dept. of Collective Health; Nursing Faculty; Universidad Nacional de Colombia; Bogotá; Colombia.

${ }^{2}$ Program of Speech and Language Pathology; Universidad Manuela Beltrán; Bogotá; Colombia.

${ }^{3}$ Faculty of Law; Pontificia Universidad Javeriana; Bogotá; Colombia.

${ }^{4}$ Dept. of Communicative Sciences $\mathcal{E}^{2}$ Disorders; Michigan State University; East Lansing; Michigan; USA.

${ }^{5}$ Program of Speech and Language Pathology; Faculty of Medicine; Universidad Nacional de Colombia; Bogotá; Colombia.

\begin{abstract}
Correspondence
Lady Catherine Cantor-Cutiva. Ciudadela Universitaria, Carrera 30 Calle 45. Facultad de Enfermería, Room 207. Telephone: +57 1 316500 ext 17081. Email:

lccantorc@unal.edu.co
\end{abstract}

\section{How to cite}

Cantor-Cutiva, Lady Catherine; Cuervo-Diaz, Diana Elizabeth; Hunter, Eric J.; MorenoAngarita, Marisol. (2021). Impairment, disability, and handicap associated with hearing problems and voice disorders among Colombian teachers. Revista de Investigación e Innovación en Ciencias de la Salud. 3(1): 04-21. https:/ / doi. org/10.46634/riics.48

Received: $29 / 10 / 2020$

Revised: $10 / 04 / 2021$

Accepted: 12/04/2021

Editor

Jorge Mauricio Cuartas Arias, Ph.D. (iD)

Coeditor

Fraidy-Alonso Alzate-Pamplona, MSc. ID

\begin{abstract}
Objectives: 1. define the occurrence of work-related hearing problems and voice disorders among teachers that have contacted the Colombian National Board of Disability Assessment (NBDA) for follow-up; 2. identify individual associated factors of hearing problems and voice disorders among teachers; 3. assess the limitations and restrictions due to hearing problems and voice disorders among these participants.
\end{abstract}

Methods: Retrospective study. The National Database of the Colombian NBDA was reviewed. Information on distributions of occupation, individual characteristics, and diagnosis code (ICD-10) was analyzed.

Results: Communication disorders among teachers that have contacted the Colombian NBDA for follow-up included voice disorders, with a prevalence of $51 \%$, and hearing problems, with a prevalence of $7 \%$. Female teachers who have contacted the Colombian NBDA for follow-up were 4 times more likely to be identified as having voice disorders compared with their male colleagues.

Conclusions: While teachers that have contacted the Colombian NBDA for follow-up have a high occurrence of voice disorders, hearing problems are more likely to be stated as a debilitating condition. One possible explanation is that teachers who contacted the Colombian NBDA for follow-up continued working even when many voice symptoms were evident, while hearing problems would prevent a teacher 
Copyright@ 2021. Fundación Universitaria María Cano. The Revista de Investigación e Innovación en Ciencias de la Salud provides open access to all its content under the terms of the Creative Commons AttributionNonCommercial-NoDerivatives 4.0 International (CC BY-NC-ND 4.0).

\section{Conflicts of Interest}

The authors have declared that no competing interests exist.

\section{Data Availability Statement}

All relevant data is in the article. For more detailed information, write to the Corresponding Author.

\section{Funding}

None. This research did not receive any specific grants from funding agencies in the public, commercial, or non-profit sectors.

\section{Disclaimer}

The content of this article is the sole responsibility of the authors and does not represent an official opinion of their institutions or the Revista de Investigación e Innovación en Ciencias de la Salud. from interacting with students, thereby affecting the teaching-learning process sooner. Nevertheless, with both voice and hearing problems, work performance and social interaction is affected, and, therefore, quality of life is reduced.

\section{Key words}

Voice disorders; hearing impairment; communication disability; impairment; disability; handicap; education; teaching; teacher; vocology.

\section{Resumen}

Objetivos: 1. definir la ocurrencia de problemas de audición y de voz relacionados con el trabajo de docentes que contactaron la Junta Nacional de Evaluación de la Discapacidad de Colombia (NBDA) para su seguimiento; 2. identificar los factores individuales asociados a los problemas de audición y voz entre los profesores; 3. evaluar las limitaciones y restricciones debidas a problemas de audición y voz asociados al trabajo entre los participantes.

Métodos: estudio retrospectivo. Se revisó la Base de Datos Nacional de la NBDA colombiana. Se analizó información sobre distribuciones de ocupación, características individuales y código de diagnóstico (CIE-10).

Resultados: Los trastornos de comunicación entre los docentes que han contactado a la NBDA colombiana para seguimiento incluyeron problemas de la voz, con una prevalencia del $51 \%$, y problemas de audición, con una prevalencia del $7 \%$. Las profesoras que se han puesto en contacto con la NBDA colombiana para el seguimiento tenían 4 veces más probabilidades de ser identificadas con trastornos de la voz en comparación con sus colegas masculinos.

Conclusiones: Si bien los maestros que contactaron a la NBDA colombiana para el seguimiento tienen una alta incidencia de trastornos de la voz, es más probable que los problemas de audición se consideren una condición debilitante. Una posible explicación es que los maestros que se comunicaron con la NBDA colombiana para el seguimiento continuaron trabajando incluso cuando muchos síntomas vocales eran evidentes, mientras que los problemas de audición evitarían que un maestro interactuara con los estudiantes, afectando así el proceso de enseñanza-aprendizaje. Sin embargo, tanto con los problemas de voz como de audición, el desempeño laboral y la interacción social se ven afectados y, por lo tanto, la calidad de vida se reduce.

\section{Palabras clave}

Problemas de la voz; discapacidad auditiva; discapacidad de la comunicación; deficiencia; discapacidad; minusvalía; educación; enseñanza; profesor; vocología.

\section{Introduction}

According to the American Speech, Language and Hearing Association (ASHA), a communication disorder "is an impairment in the ability to receive, send, process, and comprehend concepts or verbal, nonverbal and graphic symbol systems" [1]. Therefore, in general terms, a communication disorder may be represented as a hearing loss (receive), language disorder (receive, send, process and/or comprehend), and/or speech production disorder (send). Voice disorders are a common work-related health problem among teachers, with a prevalence up to $80 \%$ of all reported 
voice disorders in a year [2]. According to the Organization for Economic Cooperation and Development (OECD, an intergovernmental economic organization consisting of 35 member countries), some of the primary factors that affect the working lives of teachers include teaching hours, the extent of non-teaching duties, salaries, and average class size [3]. Further detailed in the report, approximately $35 \%$ of teachers were at least 50 years of age in 2013 , and more than $67 \%$ of teachers were women. Therefore, the analysis of the health and aging process in this occupational group should consider both work-related and individual factors in order to identify those conditions that influence teachers' health [4].

Voice disorders among teachers are multifactorial conditions. For example, previous research demonstrated that French teachers with voice disorders had higher levels of psychological distress, including an $80 \%$ greater risk of a major depressive episode and $70 \%$ for general anxiety disorder [5]. A recent systematic review of literature reported a statistically significant association between the increased occurrence of voice disorders among teachers with high stress at work and less than 6 hours/day of sleep [6]. These findings suggest a comorbidity between voice and psychological disorders and support recommendations of including techniques for stress levels reduction among occupational voice users [7]. Another important but not well-explored health problem among teachers is hearing loss: previous research involving Brazilian and Swedish teachers reported a prevalence of hearing loss and tinnitus among teachers of $25 \%$ [8] and $31 \%$ [9], respectively.

A lowering of the quality of life among teachers has been associated with work-related health problems like voice disorders and stress [10,11]. Nevertheless, there is a dearth of studies on how such health conditions influence employment retention and disability. This is partially due to the fact that few large country wide databases, which contain this type of data, exist. One such database is used by the Colombia's National Board of Disability Assessment (NBDA). This database was created for the collection, processing, and retrieval of the data on occupational diseases, with the main purpose of properly recording country-wide data from each ascertained case. This database includes information on sociodemographic characteristics, type and nature of disease, and percentage of impairment, disability, or handicap. Further, specific guidelines are outlined to perform assessments and define the nature of the disease and magnitude of the disability.

The Colombian NBDA database provides a useful tool to conduct a retrospective study, examining the influence of various health conditions on employment retention and disability. The current study proposes the following three aims: 1. define the occurrence of work-related hearing problems and voice disorders among teachers that have contacted the Colombian NBDA for follow-up; 2. identify individual associated factors of hearing problems and voice disorders among teachers; 3 . assess the limitations and restrictions (in terms of disability and handicap) due to hearing problems and voice disorders among these participants. With such information, researchers and health care providers will be able to better focus on factors hampering teachers' ability to teach effectively.

\section{Methods}

This retrospective study consists of a review of the National Database (2007-2014) of the Colombian National Board of Disability Assessment (NBDA). The NBDA contains information related to all various diseases and disabilities (occupational and non-occupational cases). The second author obtained permissions to use this database for the current analysis. 


\section{NBDA definitions and protocols}

The NBDA database was created for the collection, processing, and retrieval of the data on occupational diseases, with the main purpose of properly recording country-wide data from each case. This database includes information on sociodemographic characteristics, type and nature of disease, and percentage of impairment, disability, or handicap. The definition of these three terms was adopted from the International Classification of Impairments, Disabilities and Handicaps, published by the World Health Organization (WHO) in 1980, with the following distinctions: impairment is defined as any loss or abnormality of psychological, physiological or anatomical structure or function; disability, as any restriction or lack of ability to perform an activity in the manner or within the range considered normal for a human being; and handicap, as an impairment which prevents an individual from fulfilling a normal life role [12].

The percentage of each (impairment, disability, handicap) was calculated based on the legislation of the Colombian Minister of Work [13]: the percentage of impairment range from 0 to 50; disability, from 0 to 20; and handicap's, from 0 to 30 . The sum of the three items is the total work capacity loss. According to Colombian regulations, the pension for disability is given if the total sum exceeds $50 \%$ of total work capacity loss.

When a worker is injured or gets sick, he/she goes to a physician who determines if the issue is work-related, which means that it must be: 1 . associated with a health hazard present in the work environment and 2. included in the Colombian list of occupational diseases Decree 1477 of 2014 [14]. If the worker does not agree with the conclusion of the physician, she/ he receives a third-part assessment by one of four NBDA commissions, which consist of four professionals in charge of the evaluation and classification of the cases: two occupational physicians, one therapist or psychologist and one lawyer with specialization in health issues. Until February of 2015, the NBDA used Law 917 of 1999, which adopted the definitions of the International Classification of Impairments, Disabilities and Handicaps [12], as a guideline to perform their assessments and define the nature of the disease and magnitude of the disability.

For the determination of the percentage of impairment, disability and handicap related to voice and hearing problems, the NBDA uses instruments and protocols determined by speech and language pathologists and audiologists. Table 1 shows the conditions for determination of the percentage of disability and handicap by the NBDA.

Therefore, from the percentage's distribution, the focus of the evaluation of disability is on health conditions and mobility restrictions, whereas for handicap is on occupation and mobility.

\section{General information}

From 2007 to 2014, the NBDA received 78,920 claims, corresponding to 44,954 people of all around the country. Among the procedures sent to the NBDA, 22,655 cases (around $50 \%$ ) were identified as work-related events (work accident or occupational disease). A case was "defined" as work related if the disease was identified as a consequence of the worker's working conditions. In order to define this, the members of the NBDA request evaluations and reports of the physical and environmental conditions to which the worker was exposed. Additionally, the worker provides his/her medical history. With this information, the members of the NBDA evaluate the association between either the accident or the disease with the working conditions to determine the work-relatedness of the event. 


\begin{tabular}{|c|c|}
\hline Condition & Maximum possible score \\
\hline \multirow{6}{*}{ Disability } & Up to $3 \%$ of communication disability \\
\hline & Up to $3 \%$ personal care \\
\hline & Up to $3 \%$ locomotion \\
\hline & Up to $3 \%$ posture \\
\hline & Up to $3 \%$ skill \\
\hline & $\begin{array}{l}\text { Up to } 3 \% \text { of disability under low tolerance situations, such } \\
\text { as temperature, lighting, and stress at work }\end{array}$ \\
\hline \multirow{7}{*}{ Handicap } & $2.5 \%$ for handicap in orientation \\
\hline & $2.5 \%$ for handicap in physical independence \\
\hline & $2.5 \%$ for handicap in movement \\
\hline & $15 \%$ for occupational handicap \\
\hline & $2.5 \%$ for social integration \\
\hline & $2.5 \%$ for economic handicap \\
\hline & $\begin{array}{l}2.5 \% \text { for age (younger than } 18 \text { years old and older than } 55 \\
\text { years old with higher percentages) }\end{array}$ \\
\hline
\end{tabular}

As shown in Figure 1, among the work-related identified events, 13,890 people were qualified with a loss of work capacity between $5 \%$ and $49.9 \%$. This means that approximately $60 \%$ of the claims were qualified with a partial permanent disability (they had limitations to their ability to continue performing their jobs as they did before the accident or disease). The quantification of the loss of work capacity was made based on Decree 917 of 1999, which defines the criteria for determination of the percentage of impairment, disability, and handicap [15]. According to the Article 8 of this Decree, total percentage of work capacity loss is defined using three aspects: impairment ( $0 \%$ to $50 \%)$, disability $(0 \%$ to $20 \%)$, and handicap (0\% to 30\%). This Colombian Decree is based on the Guides to the Evaluation of Permanent Impairment, published by the American Medical Association [16].

The database used for this study contains information on individual factors, such as occupation, gender, age, level of education, marital status, city, clinical diagnosis code (according to ICD-10), percentage of impairment, percentage of disability, and percentage of handicap.

\section{Participants}

The review of the database identified 95 Colombian teachers who had contacted the NBDA for follow-up and were listed in the NBDA between 2007 and 2014. Of those, teachers with communication disorders were identified $(\mathrm{n}=95)$. 


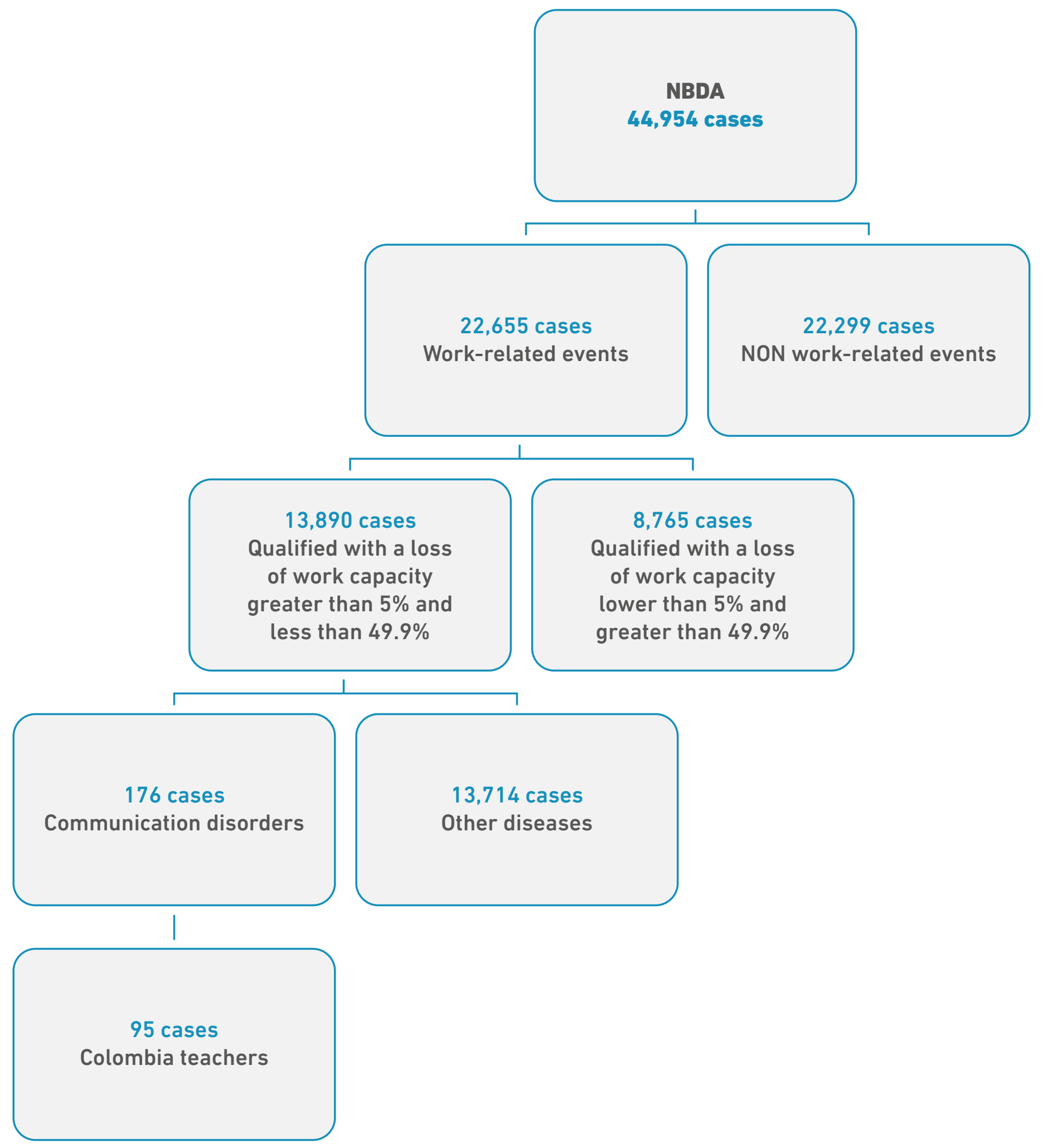

Figure 1. Flowchart of NBDA search and selection of Colombian teachers with communication disorders 
As shown in Table 2, the clinical diagnosis codes considered for the current study to be related to hearing problems and voice disorders were: J37.0 (Chronic laryngitis), J38.1 (Polyp of vocal cord and larynx), J38.2 (Nodules of vocal cords), J38.3 (Other diseases of vocal cords), R49.0 (Dysphonia), H81.3 (Other peripheral vertigo), H90.3 (Sensorineural hearing loss, bilateral), and H90.5 (Sensorineural hearing loss, unspecified).

\begin{tabular}{|c|c|c|}
\hline Characteristic & $\mathbf{N}$ & $\%$ \\
\hline \multicolumn{3}{|l|}{ Gender } \\
\hline Male & 17 & 18 \\
\hline Female & 78 & 82 \\
\hline \multicolumn{3}{|l|}{ Education level } \\
\hline Graduate & 18 & 19 \\
\hline Undergraduate & 70 & 74 \\
\hline Missing values & 7 & 7 \\
\hline \multicolumn{3}{|l|}{ Marital Status } \\
\hline Married & 46 & 48 \\
\hline Living with partner & 5 & 5 \\
\hline Single & 38 & 41 \\
\hline Missing values & 6 & 6 \\
\hline \multicolumn{3}{|l|}{ Age } \\
\hline 20-39 years & 21 & 22 \\
\hline 40-49 years & 25 & 27 \\
\hline $50-59$ years & 42 & 44 \\
\hline $60-79$ years & 7 & 7 \\
\hline \multicolumn{3}{|l|}{ Diagnosis } \\
\hline Other diagnosis (mental and musculoskeletal disorders) & 40 & 42 \\
\hline \multicolumn{3}{|l|}{ Hearing problems } \\
\hline H81.3 (Other peripheral vertigo) & 1 & 1 \\
\hline H90.3 (Sensorineural hearing loss, bilateral) & 4 & 4 \\
\hline H90.5 (Sensorineural hearing loss, unspecified) & 2 & 2 \\
\hline \multicolumn{3}{|l|}{ Voice disorders } \\
\hline J37.0 (Chronic laryngitis) & 8 & 9 \\
\hline J38.1 (Polyp of vocal cord and larynx) & 1 & 1 \\
\hline J38.2 (Nodules of vocal cords) & 8 & 9 \\
\hline J38.3 (Other diseases of vocal cords) & 4 & 4 \\
\hline R49.0 (Dysphonia) & 27 & 28 \\
\hline
\end{tabular}




\section{Definitions of voice disorders and hearing problems in the NBDA database}

The NBDA gives specific procedures for the identification and classification of health conditions, including of voice disorders and hearing problems.

\section{Voice disorders}

As part of the required examinations to define a voice disorder, an ENT specialist performed a clinical exam, including a laryngoscopy. After the examinations, the NBDA analyzed the results, which included a diagnosis code (ICD-10). For voice disorders, the clinical diagnosis codes considered, according to ICD-10, were listed in Table 2. After receiving information related to the working conditions and the medical history, the members of the NBDA determined the level of impairment. This level was determined by considering three questions: 1 . how well could the teacher make himself/herself be heard? 2. how intelligible was the teacher? and 3. how efficient was the speech of the teacher? The percentage of impairment was determined based on Table 13.8, Impairment related with speech problems, in the Decree 917 of 1999 [15].

\section{Hearing problems}

Teachers went through a complete hearing assessment (bone and air conduction audiometry + speech audiometry + impedance audiometry) at least three times for 1-2 months. Considering the Decree 917 of 1999, the hearing threshold level, using audiometry, was defined based on the pure tone average at frequencies of $0.5,1,2$, and $4 \mathrm{kHz}$. Binaural impairment was determined by means of the following formula [15]:

Binaural hearing impairment $(\%)=(5 \mathrm{x} \%$ hearing impairment better ear $)+(\%$ hearing impairment poorer ear) x 0.5

The percentage of hearing impairment was determined based on Table 13.7, Binaural Hearing Impairment, in the Decree 917 of 1999 [15].

\section{Statistical Analysis}

Using the information from the 95 teachers found in the NBDA, data on individual factors (gender, age, level of education, marital status), diagnosis code, and percentage of work capacity lost were extracted from the NBDA database and analyzed using SPSS 22 software. Descriptive statistics were used for characteristics of the study population. The Shapiro-Wilk test was used to evaluate whether variables were normally distributed. To assess the association between individual characteristics and work-related hearing problems and voice disorders among teachers, a multiple logistic regression analysis was used. Variables with a p-value below 0.20 in the univariate analyses were included in the multivariate analysis in order to avoid residual confounding [17], and were only retained when the p-value reached the conventional level of significance of 0.05 . The magnitude of the association was expressed by the odds ratio (OR), and the statistical significance as the $95 \%$ confidence interval (95\% CI).

\section{Results}

In total, epidemiological records from 95 teachers with communication disorders were available in the NBDA database; all were used for this study. Of these 95 teachers, most were females $(82 \%)$, and most were between $50-59$ years of age (44\%). Table 1 shows that $51 \%$ of the teachers were identified with voice disorders, whereas $7 \%$ were identified with hearing problems. 


\section{Individual factors associated with hearing problems and voice disorders among teachers}

Table 3 shows the associated factors of hearing problems and voice disorders among the 95 teachers. In the univariate analysis, gender was significantly associated with voice disorders and hearing problems. Nevertheless, after adjustments for significant factors in the univariate analysis (marital status and age), the association between gender with hearing problems did not remain significant. Multivariate analysis shows that participating female teachers were 4 times more likely to be identified with voice disorders compared with their male colleagues. The results of the multivariate analysis also show that teachers 50 years old or older were less likely $(\mathrm{OR}=0.3)$ to be identified with voice disorders by the NBDA than younger teachers.

\begin{tabular}{|c|c|c|c|c|}
\hline \multirow[b]{2}{*}{ Variable } & \multicolumn{2}{|c|}{ Voice disorders } & \multicolumn{2}{|c|}{ Hearing problems } \\
\hline & OR & $95 \% \mathrm{Cl}$ & OR & $95 \% \mathrm{Cl}$ \\
\hline \multicolumn{5}{|l|}{ Gender } \\
\hline Male & 1 & Referent & 1 & Referent \\
\hline Female & $3.9^{*}$ & $(1.1-13.7)$ & 0.3 & $(0.1-1.4)$ \\
\hline \multicolumn{5}{|l|}{ Marital Status } \\
\hline Married & & & 1 & Referent \\
\hline No married & & & 3.5 & $(0.6-19.7)$ \\
\hline \multicolumn{5}{|l|}{ Age } \\
\hline Younger than $50 \mathrm{y} / 0$ & 1 & Referent & & \\
\hline 50 years old or older & $0.3^{*}$ & $(0.1-0.6)$ & & \\
\hline
\end{tabular}

\section{Impairment, disability, and handicap among teachers}

Among the 95 Colombian teachers with hearing problems and voice disorders, the occurrence of hearing problems was lower than voice disorders. However, the members of the Colombian NBDA considered that hearing problems caused higher impairment, disability and handicap compared with voice disorders (impairment $=9 \%$ vs. $2 \%$, disability $=2 \%$ vs. $1 \%$, and handicap $=6 \%$ vs. $3 \%$ ). Figure 2 . a shows the mean values and standard error of impairment by hearing problems and voice disorders. Figure 2.b and Figure 2.c show that voice disorders, although more prevalent among included teachers, were defined by the NBDA with lower disability and handicap values (respectively). 
Figure 2. Mean percentage score among 55 Colombian teachers identified with communication disorders by the NBDA: (a) mean percentage of impairment score per communication disorder, (b) mean percentage of disability score per communication disorder, (c) mean percentage of handicap score per communication disorder.

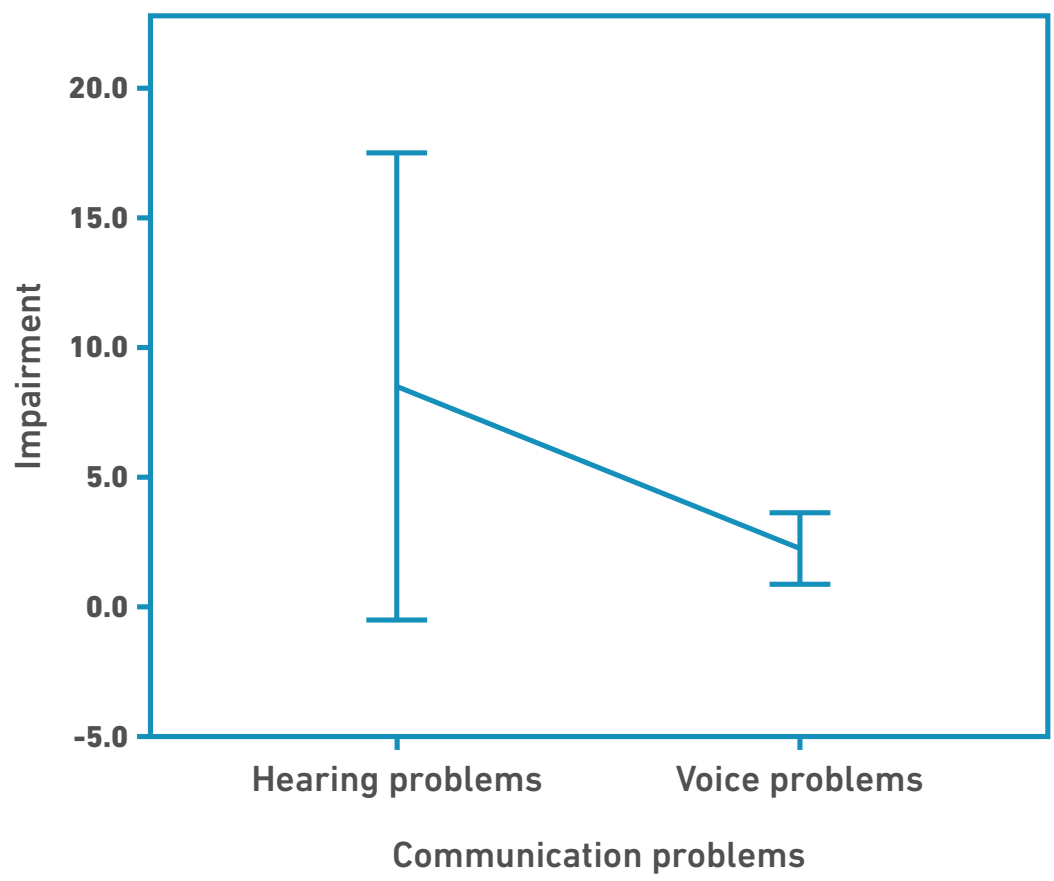

(a) Mean percentage of impairment score per communication disorder

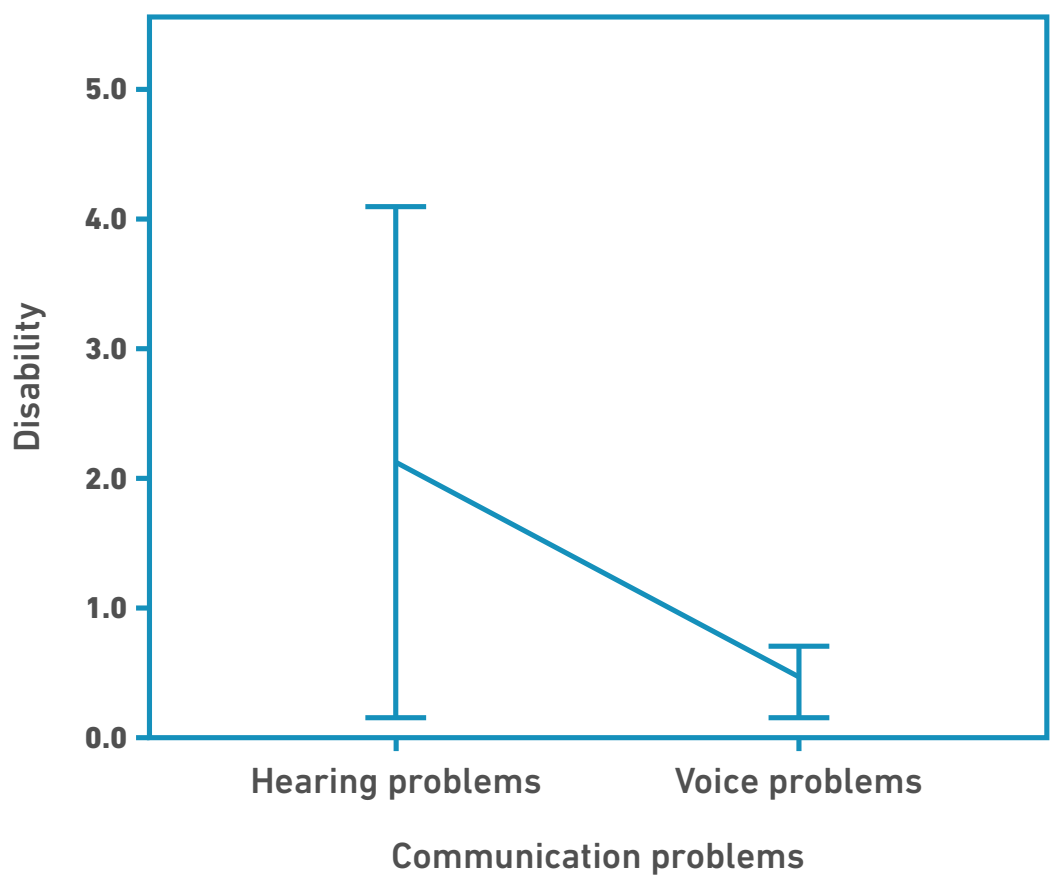

(b) Mean percentage of disability score per communication disorder 


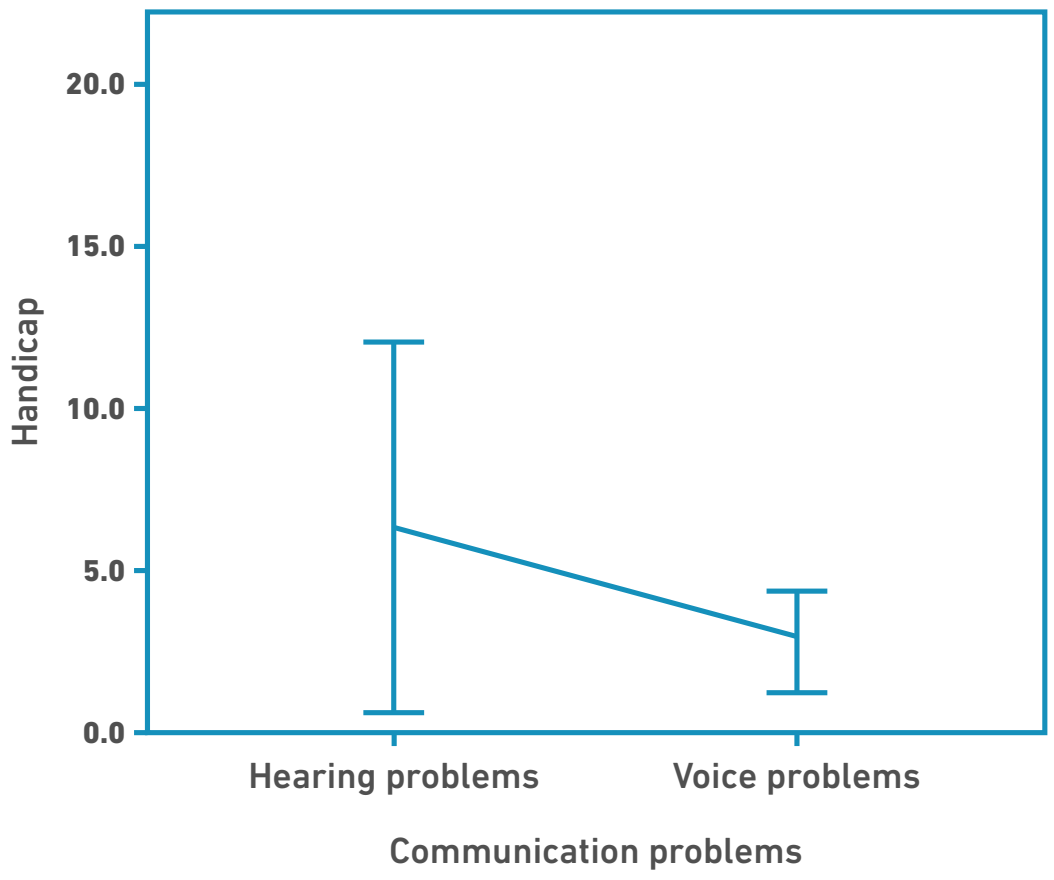

(c) Mean percentage of handicap score per communication disorder

\section{Discussion}

This retrospective study of teachers that have contacted the Colombian National Board of Disability Assessment (NBDA) for follow-up aimed to determine the impairment, disability, and handicap associated with hearing problems and voice disorders among Colombian teachers, as well as to assess the individual associated factors. Results are dependent on the NBDA criteria and protocols. Based on the data within those criteria and protocols, our results indicated that although voice disorders were more prevalent than hearing problems, since hearing problems can also affect the social integration in addition to the occupational handicap, they were identified with higher impact upon the teachers by the members of the Colombian NBDA.

In this study, around $51 \%$ of Colombian teachers were identified as having a work-related voice disorder. Although our participants were teachers that have contacted the Colombian NBDA for follow-up, our results are in line with previous studies that reported a point prevalence of $45 \%$ among Colombian teachers [18], and 57\% among Spanish teachers [19]. It has been reported that teachers have higher likelihood of having voice disorders compared with other occupations, due in part to high vocal demands, poor acoustic conditions inside the classrooms, and lack of vocal training [2, 20-22]. Cantor and Burdorf (2016) suggested that voice disorders are persistent health problems among teachers, which is reflected in a high prevalence, incidence and chronicity during one year follow-up [23]. This high persistence of voice problems among teachers may be partially explained because voice disorders as a health problem among teachers are not identified as a health problems by them, which means that teachers with voice complaints continue working as much as possible despite their voice symptoms $[24,25]$, thereby aggravating them. From our results, it seems that physicians do 
not identify work-related voice disorders easily either, considering $51 \%$ of the teachers looking for follow-up were identified with a work-related voice disorder, whereas $7 \%$ of them were identified with a work-related hearing problem.

Concerning the individual factors associated with voice disorders, our results suggested that female teachers in Colombia that have contacted the Colombian NBDA for follow-up were more likely to have work-related voice disorders compared with male teachers $(\mathrm{OR}=$ 3.9), whereas teachers 50 years old or older were less likely to present work-related voice disorders compared with younger teachers $(\mathrm{OR}=0.3)$. These findings are in line with previous studies that report that females (teachers and non-teachers) have a higher prevalence of voice disorders generally [26] and that female teachers are particularly at risk of being referred to vocal health professionals [27]. This voice-gender disparity may stem from gender differences related to both laryngeal and non-laryngeal physiology, as well as the effects of hormones and behavior [28]. As for the age effect, there are two possible explanations. First, it is likely that more experienced teachers are easily identified with a work-related voice disorder during the first examination of the physician. Second, more experienced teachers are accustomed to experiencing occupationally related vocal fatigue or voice problems and because they consider it normal, are less likely to pursue disability claims.

In this study, of the 95 teachers that have contacted the Colombian NBDA for follow-up, we found 7\% with work-related hearing problems. This finding is lower than the Brazilian study of Garcia Martins et al. (2007) and the Swedish study of Sjödin et al. (2012), which found a prevalence of hearing loss of 25\% [8] and 46\% [9], respectively. One possible explanation for the decreased prevalence reported in our study is our population characteristics. From our results, it seems likely that physicians doing the first examination were better at detecting and accepting work-related hearing problems than work-related voice disorders. Therefore, a small percentage of teachers with hearing problems contacted the Colombian NBDA for follow-up. This finding may be an indication that physicians identified easier hearing problems than voice disorders as work-related health problems, even though both communication processes impact quality of work and quality of life among teachers. Another explanation may be related with the type of assessment process implemented for the definition of hearing loss. In the present study, teachers were required to undergo a complete hearing assessment (which included not only a bone and air conduction audiometry, but also speech audiometry and impedance audiometry) at least three times for 1-2 months. In Colombia, the repeated measurements are used to assess the occurrence of a persistent hearing problem and to diagnose the type and severity of hearing loss (also the work-relatedness). In contrast, Garcia Martins et al. reported that participants underwent pure tone audiometry and speech audiometry (once), whereas Sjödin et al. used self-reports about the subjective hearing status; therefore, these reduced requirements would likely show a higher prevalence of hearing loss due to the type of evaluation implemented. This finding aligns with previous voice disorder studies, which found an overestimation of teachers' self-reported voice disorders compared with perceptual identification by speech-language pathologists [2]. A third possible explanation may be the thresholds defined in the studies. In the Brazilian study, hearing loss was defined as a $25 \mathrm{~dB}$ reduction of the audiometric threshold at 4,000 and $6,000 \mathrm{~Hz}$ only [8]. In the Swedish study, hearing loss was defined as a mean threshold larger than $35 \mathrm{~dB}$ HL for the frequencies 2000 $\mathrm{Hz}$ and $3000 \mathrm{~Hz}$, and a mean threshold larger than 45dBHL for the frequencies $4000 \mathrm{~Hz}$ and 6000 [9]. The Brazilian and Swedish studies used just high frequencies to define hearing loss, whereas the NDBA defines hearing loss using the ear average for four frequencies $0.5,1,2$, 
and $4 \mathrm{kHz}$. These differences in the definition of hearing loss thresholds and used frequencies may cause higher prevalence of hearing loss cases in the Brazilian and Swedish studies.

Although there is an important number of publications on the relationship between teaching and classroom acoustics with occurrence of communicative disorders among teachers, most of them are focused on voice disorders [23,29-31], with few studies on the occurrence and consequences of hearing loss among teachers [32,33]. Previous studies on noise and voice concluded that acoustics and noise conditions are associated factors for the onset and persistence of voice disorders among teachers $[2,29]$. One explanation for this association between noise and voice is the Lombard effect [34], defined as the modification of the voice production in the presence of noise due to the masking of voice. Therefore, under noisy conditions, teachers may tend to increase their vocal effort [35] and raise their voices to guarantee the success of the communication process, which may lead to the development of voice disorders $[36,37]$.

Publications on noise and hearing have studied the effect of noise exposure among music teachers [38-40]. Previous studies have reported mean values of noise levels in occupied classrooms ranging from $72 \mathrm{dBA}$ [29] to $76 \mathrm{dBA}$ [41] with noise sources inside the classrooms such as toys and classroom noise during different activities $[9,42]$. Although these values do not exceed the permissible exposure limits as currently defined by international standards, $90 \mathrm{dBA}$ for an 8-hour day with a $5 \mathrm{dBA}$ exchange rate (which means that for every $5 \mathrm{dBA}$ increase, the amount of exposure time is cut in half), they can affect hearing functioning and voice production among teachers [43]. Therefore, consistent noise levels inside the classrooms over time might affect the communication process, as well as the general health status of teachers $[29,42]$. Lindblad et al. (2014) reported that teachers showed similar results as industrial workers for speech recognition in noise and tinnitus, which may suggest lesions in the inner hair cell area due to exposure to sudden loud sounds, such as screams of the children [44]. Since hearing is the main tool for receiving verbal information, its breakdown negatively influences the teaching-learning process. As a result, teachers need to adjust their teaching strategies to maintain an adequate learning environment inside the classrooms. Moreover, previous authors have reported that work-related noise may contribute to physical and mental health disorders in teachers [45].

Concerning the third aim of this study, our findings indicated that voice disorders, although more frequent among teachers that have contacted the Colombian NBDA for follow-up, were identified by the members of the Colombian NBDA with lower percentage of handicap compared with hearing problems. In this study, the members of the NBDA determined that voice disorders did not interfere strongly with the daily activities of teachers. The average handicap percentage for teachers with voice disorders was 3\%, whereas for hearing problems was $6 \%$. Even though the voice is a teacher's primary occupational tool, teachers may consider voice disorders to be a normal part of the health-work process. Therefore, it is common that teachers accept their voice disorders and continue teaching despite vocal health issues, which means that the perceived limitation in activity due to voice disorders is lower than hearing problems. Nevertheless, previous research has reported that teachers who continue teaching during periods of vocal impairment incur significant direct and indirect costs due to productivity loss, absenteeism and use of healthcare system [46].

Moreover, considering the focus of the evaluation of disability performed by the NBDA, it seems likely that communication problems have low percentage of disability and handicap, 
even though this does not reflect the impact of these problems in daily life and quality of life. Our results reflect this weakness in the evaluation process and highlight the need of implement specific protocols to assess different type of disabilities.

This study has several limitations. First, there was a limited sample size from those seeking medical help and being included in the database. Second, this population was limited further because it included exclusively workers who did not agree with their initial evaluations and looked for a third-part assessment by the NBDA, which hampers the ability to generalize the findings. Additionally, as with any large-scale data collection and database, analysis and results are dependent on the criteria and protocols (and compliance to those protocols). Finally, the study did not include other variables of interest (e.g., level of teaching) because they were not included in the database, which may limit the possibility of analyzing other important factors associated with the occurrence of communication problems among teachers.

In conclusion, while teachers that have contacted the Colombian NBDA for follow-up have a high occurrence of voice disorders, hearing problems is more likely to be stated as a more severe disability than a voice disorder. One possible explanation is that teachers who contacted the Colombian NBDA for follow-up did continue working even when many symptoms were evident, while hearing problems would prevent a teacher from interacting with students, thereby affecting the teaching-learning process. Nevertheless, with both voice and hearing problems, work performance and social interaction is affected, and therefore quality of life is reduced. For this reason, it is important to design and implement work-based communicative health promotion programs that aim to reduce the high occurrence of voice problems and the high limitation of hearing problems for teachers. A first step for the design of such programs is the definition of an epidemiologic profile of work-related voice disorders among teachers. This profile would help lawmakers and health professionals establish guidelines on the prevention of the most common work-related diseases among teachers. Future research is also needed to clarify the natural variation and work-relatedness of hearing problems among teachers.

\section{References}

1. American Speech-Language-Hearing Association (ASHA). Definitions of communication disorders and variations. Maryland: American Speech-Language-Hearing Association; 1993. Doi: https://doi.org/10.1044/policy.RP1993-00208

2. Cantor Cutiva L, Vogel I, Burdorf A. Voice disorders in teachers and their associations with work-related factors: A systematic review. Journal of Communication Disorders. 2013;46(2):143-55. Doi: https://doi.org/10.1016/j.jcomdis.2013.01.001

3. OECD. Education at a Glance 2015: OECD Indicators. Paris: OECD Publishing; 2015.

4. Simberg S, Santtila P, Soveri A, Varjonen M, Sala E, Sandnabba NK. Exploring genetic and environmental effects in dysphonia: a twin study. Journal of Speech, Language, and Hearing Research. 2009;52(1):153-63. Doi: https://doi.org/10.1044/10924388(2008/07-0095)

5. Nerrière E, Vercambre M-N, Gilbert F, Kovess-Masféty V. Voice disorders and mental health in teachers: a cross-sectional nationwide study. BMC Public Health. 2009;9(1):370. Doi: https://doi.org/10.1186/1471-2458-9-370 
6. Carrillo-Gonzalez, A, Camargo-Mendoza, M, \& Cantor-Cutiva, LC.. Relationship between sleep quality and stress with voice functioning among college professors: a systematic review and meta-analysis. Journal of Voice. 2021;35(3):499-e13. Doi: https://doi. org/10.1016/j.jvoice.2019.11.001

7. Carrillo-González A, Atará-Piraquive ÁP. Vocal health and stress: the occupational voice users' perspective during the COVID-19 pandemic. Revista de Investigación e Innovación en Ciencias de la Salud. 2020;2(2):102-110. Doi: https://doi.org/10.46634/riics.38

8. Garcia Martins RH, Mendes Tavares EL, Lima Neto AC, Fioravanti MP. Occupational hearing loss in teachers: a probable diagnosis. Revista Brasileira de Otorrinolaringologia. 2007;73(2):239-44. Doi: https://doi.org/10.1016/S1808-8694(15)31072-7

9. Sjödin F, Kjellberg A, Knutsson A, Landström U, Lindberg L. Noise exposure and auditory effects on preschool personnel. Noise Health. 2012;14(57):72-82. Doi: https://doi. org/10.4103/1463-1741.95135

10. Yang X, Ge C, Hu B, Chi T, Wang L. Relationship between quality of life and occupational stress among teachers. Public Health. 2009;123(11):750-5. Doi: https://doi. org/10.1016/j.puhe.2009.09.018

11. Cantor Cutiva L, Burdorf A. Factors associated with voice-related quality of life among teachers with voice complaints. Journal of Communication Disorders. 2014;52:134-42. Doi: https://doi.org/10.1016/j.jcomdis.2014.05.003

12. World Health Organization (WHO). International classification of impairments, disabilities and handicaps: a manual of classification relating to the consequences of disease. Geneve: World Health Organization; 1980.

13. Presidencia de la República de Colombia. Decree 1295 of 1994 (Decreto 1295 de 1994). In: Ministerio de Trabajo y Seguridad Social, editor. Bogotá D.C.; 1994.

14. Presidencia de la República de Colombia. Decree 1477 of 2014 (Decreto 1477 de 2014). Bogotá D.C.; 2014.

15. Presidencia de la República de Colombia. Decree 917 of 1999 (Decreto 917 de 1999). Bogotá D.C.; 1999.

16. Rondinelli R, Genovese E, Katz R, Mayer T, Mueller K, Ranavaya M. Guides to the evaluation of permanent impairment. Chicago: American Medical Association press; 2009. Doi: https://doi.org/10.1001/978-1-57947-888-9

17. Maldonado G, Greenland S. Simulation Study of Confounder-Selection Strategies. American Journal of Epidemiology. 1993;138(11):923-36. Doi: https://doi.org/10.1093/ oxfordjournals.aje.al16813

18. Cantor Cutiva L, Fajardo A, Burdorf A. Associations between self-perceived voice disorders in teachers, perceptual assessment by speech-language pathologists, and instrumental analysis. International Journal of Speech-Language Pathology. 2016;18(6):550-9. Doi: https://doi.org/10.3109/17549507.2016.1143969 
19. Preciado-Lopez J, Perez-Fernandez C, Calzada-Uriondo M, Preciado-Ruiz P. Epidemiological study of voice disorders among teaching professionals of La Rioja, Spain. Journal of Voice. 2008;22(4):489-508. Doi: https://doi.org/10.1016/j.jvoice.2006.11.008

20. Fritzell B. Voice disorders and occupations. Log Phon Vocol. 1996;21(1):7-12. Doi: https://doi.org/10.3109/14015439609099197

21. Pekkarinen E, Himberg L, Pentti J. Prevalence of vocal symptoms among teachers compared to nurses-a questionnaire study. Scandinavian Journal of Logopedics and Phoniatrics. 1992;17:112-7. Doi: https://doi.org/10.3109/14015439209098721

22. Roy N, Merrill R, Thibeault S, Gray S, Smith E. Voice disorders in teachers and the general population: Effects on work performance, attendance, and future career choices. Journal of Speech, Language, and Hearing Research. 2004;47(3):542-51. Doi: https:// doi.org/10.1044/1092-4388(2004/042)

23. Cantor Cutiva LC, Burdorf A. Work-related determinants of voice complaints among school workers: An eleven-month follow-up study. American Journal of Speech-Language Pathology. 2016;25(4):590-7. Doi: https://doi.org/10.1044/2016_AJSLP-14-0191

24. Grillo MHM, Penteado RZ. Impacto da voz na qualidade de vida de professore(a)s do ensino fundamental. Pró-Fono Revista de Atualização Científica. 2005;17:311-20. Doi: https://doi.org/10.1590/s0104-56872005000300006

25. Penteado RZ, Pereira IMTB. Qualidade de vida e saúde vocal de professores. Revista de Saúde Pública. 2007;41:236-43. Doi: https://doi.org/10.1590/S003489102007000200010

26. Roy N, Merrill R, Thibeault S, Parsa R, Gray S, Smith E. Prevalence of voice disorders in teachers and the general population. Journal of Speech, Language, and Hearing Research. 2004;47(2):281-93. Doi: https://doi.org/10.1044/1092-4388(2004/023)

27. Mattiske J, Oates J, Greenwood K. Vocal problems among teachers: a review of prevalence, causes, prevention, and treatment. Journal of Voice. 1998;12(4):489-99. Doi: https://doi.org/10.1016/S0892-1997(98)80058-1

28. Hunter EJ, Tanner K, Smith ME. Gender differences affecting vocal health of women in vocally demanding careers. Logopedics Phoniatrics Vocology. 2011;36(3):128-36. Doi: https://doi.org/10.3109/14015439.2011.587447

29. Cantor Cutiva L, Burdorf A. Effects of noise and acoustics in schools on vocal health in teachers. Noise Health. 2015;17(74):17-22. Doi: https://doi.org/10.4103/14631741.149569

30. De Medeiros A, Barreto S, Assuncao A. Voice disorders (dysphonia) in public school female teachers working in Belo Horizonte: prevalence and associated factors. Journal of Voice. 2008;22(6):676-87. Doi: https://doi.org/10.1016/j.jvoice.2007.03.008

31. Ilomaki I, Leppanen K, Kleemola L, Tyrmi J, Laukkanen A, Vilkman E. Relationships between self-evaluations of voice and working conditions, background factors, and phoniatric findings in female teachers. Logopedics Phoniatrics Vocology. 2009;34(1):20-31. Doi: https://doi.org/10.1080/14015430802042013 
32. Servilha EAM, Delatti MdA. Noise perception in the workplace and auditory and extra-auditory symptoms referred by university professors. Jornal da Sociedade Brasileira de Fonoaudiologia. 2012;24(3):233-8. Doi: https://doi.org/10.1590/S217964912012000300008

33. Jiang T. Can noise levels at school gymnasia cause a hearing loss: A case study of a physical education teacher. Journal of the Acoustical Society of America. 1997;101(5):3069. Doi: https://doi.org/10.1121/1.418754

34. Lane H, Tranel B. The Lombard Sign and the Role of Hearing in Speech. Journal of Speech and Hearing Research. 1971;14(4):677-709. Doi: https://doi.org/10.1044/ jshr. 1404.677

35. Hunter EJ, Cantor-Cutiva LC, Van Leer E, Van Mersbergen M, Nanjundeswaran CD, Bottalico P, et al. Toward a Consensus Description of Vocal Effort, Vocal Load, Vocal Loading, and Vocal Fatigue. Journal of Speech, Language, and Hearing Research. 2020;2:509-532. Doi: https://doi.org/10.1044/2019_JSLHR-19-00057

36. Vilkman E. Voice problems at work: A challenge for occupational safety and health arrangement. Folia Phoniatr Logop. 2000 Jan-Jun;52(1-3):120-5. Doi: https://doi. org/10.1159/000021519

37. Zollinger SA, Brumm H. The evolution of the Lombard effect: 100 years of psychoacoustic research. Behaviour. 2011;148(11-13):1173-98. Doi: https://doi. org/10.1163/000579511X605759

38. Cutietta R, Klich R, Royse D, Rainbolt H. The Incidence of Noise-Induced Hearing Loss among Music Teachers. Journal of Research in Music Education. 1994;42(4):31830. Doi: https://doi.org/10.2307/3345739

39. Behar A, MacDonald E, Lee J, Gui J, Kunov H, Wong W. Noise exposure of music teachers. Journal of Occupational and Environmental Hygiene. 2004 Apr;1(4):243-7. Doi: https://doi.org/10.1080/15459620490432178

40. Chesky K. Schools of music and conservatories and hearing loss prevention. International Journal of Audiology. 2011;50(sup1):S32-S7. Doi: https://doi.org/10.3109/1499202 7.2010 .540583

41. Ramig LO, Verdolini K. Treatment Efficacy: Voice Disorders. Journal of Speech, Language, and Hearing Research. 1998;41(1):S101-S16. Doi: https://doi.org/10.1044/ jsthr.4101.s101

42. McAllister AM, Granqvist S, Sjölander P, Sundberg J. Child voice and noise: a pilot study of noise in day cares and the effects on 10 children's voice quality according to perceptual evaluation. Journal of Voice. 2009;23(5):587-93. Doi: https://doi.org/10.1016/j. jvoice.2007.10.017

43. Occupational Safety and Health Administration (OSHA). 1910.95, Occupational noise exposure. In: United States Department of Labor, editor. Washington DC: United States Department of Labor; 2011. 
44. Lindblad A-C, Rosenhall U, Olofsson Å, Hagerman B. Tinnitus and Other Auditory Problems-Occupational Noise Exposure below Risk Limits May Cause Inner Ear Dysfunction. PloS one. 2014;9(5):e97377. Doi: https://doi.org/10.1371/journal.pone.0097377

45. Sala E, Rantala L. Acoustics and activity noise in school classrooms in Finland. Applied Acoustics. 2016;114:252-9. Doi: https://doi.org/10.1016/j.apacoust.2016.08.009

46. Cantor Cutiva L, Burdorf A. Medical Costs and Productivity Costs Related to Voice Symptoms in Colombian Teachers. Journal of Voice. 2015;29(6):776.e15-.e22. Doi: https://doi.org/10.1016/j.jvoice.2015.01.005 